\title{
PRESCRIÇÃO E DECADÊNCIA
}

\author{
IVES GANDRA DA SILVA MARTINS*
}

Em 1976, coordenei o I Simpósio Nacional de Direito Tributário do Centro de Extensão Universitária, subordinado ao tema "Decadência e Prescrição". O livro, editado pela Editora Resenha Tributária e o CEU, teve a participação dos seguintes autores: Aires Fernandino Barreto, Bernardo Ribeiro de Moraes, Carlos da Rocha Guimarães, Edvaldo Brito, Fábio Fanucchi, Francisco de Assis Praxedes, Ives Gandra da Silva Martins, José Carlos Graça Wagner, Leonel de Andrade Velloso, Noé Winkler, Paulo de Barros Carvalho, Rafael Moreno Rodrigues, Roberto Oscar Freytes, Rubens Approbato Machado, Sebastião de Oliveira Lima e Ylves José de Miranda Guimarães.

Concluíram, na ocasião, os tributaristas de quase todos os Estados do Brasil, respondendo às questões formuladas, o seguinte:

“I) Que é a constituição definitiva do crédito tributário?

CONCLUSÃO DO PLENÁRIO: Há constituição definitiva do crédito tributário quando houver ato administrativo regularmente notificado ou homologação, nos termos do art. 150 do CTN, que preencha requisitos do art. 142 do referido Código, tornando a obrigação extinta (art. 150 do CTN) ou líquida, isto é, certa quanto à sua existência e determinada quanto ao seu objeto (art. 1533 do Código Civil) - (conclusão majoritária).

2) $O$ auto de infração representa a constituição do crédito tributário?

CONCLUSÃO DO PLENÁRIO: $O$ auto de infração, enquanto simplesmente ato de proposição de penalidade, não é constitutivo de crédito tributário;

* Professor Emérito da Universidade Mackenzie e da Escola de Comando e Estado Maior do Exército, Presidente do Conselho de Estudos Jurídicos da Federação do Comércio do Estado de São Paulo e do Centro de Extensão Universitária - CEU. 
será constitutivo na parte em que contiver exigência de tributo, se observados os requisitos do art. 142 do CTN (conclusāo majoritária).

$O$ auto de infração não é constitutivo do crédito tributário por não ser ato de fixação da obrigação tributária (3 votos).

3) Existe uma constituição provisória do crédito tributário?

CONCLUSÃO DO PLENÁRIO: Não há lançamento provisório. A possibilidade de alteração do lançamento não impede que seja considerado ato completo. Admitir o contrário resultaria na impossibilidade de considerar definitivo o lançamento de tributo notificado ao contribuinte e não impugnado, pois, neste caso, o lançamento pode ser revisto com base em cerro de fato (conclusão majoritária com 1 voto divergente).

4) A exigibilidade do crédito tributário é elemento fundamental na sua constituição, ou sua suspensão não altera a natureza daquele?

CONCLUSÃO DO PLENÁRIO: A exigibilidade do crédito tributário, porque inerente a ele, é elemento fundamental à sua constituição; a sua suspensão não altera a natureza do crédito (conclusão unânime).

5) A suspensão da exigibilidade do crédito tributário paralisa a prescrição ou apenas a interrupção tem este poder?

CONCLUSÃO DO PLENÁRIO: A suspensão da exigibilidade do crédito tributário acarreta a suspensão da contagem do prazo prescricional, não havendo, nesse sentido, que falar em interrupção. A suspensão da contagem, nesse caso, fica condicionada à observância de prazos do processo tributário administrativo que, se inobservados, determinam a contagem intercorrente, pelas determinações do art. 151, inc. III do CTN (conclusão majoritária).

O prazo de prescrição só se suspende nos casos previstos em lei. Assim, a suspensão da exigibilidade do crédito tributário não paralisa a prescrição, salvo a hipótese contida no art. 155, parágrafo único do CTN (proposta da Comissão Redatora das Propostas a serem apresentadas em Plenário, que foi rejeitada pelo plenário, por maioria de votos).

6) Em que casos se deve utilizar o recurso do protesto judicial, segundo hipóteses de interrupção da prescrição?

CONCLUSÃO DO PLENÁRIO: O protesto judicial é medida prevista no Código de Processo Civil visando, entre outras finalidades, a proceder a conservação e ressalva de direitos de quem o promove (art. 867 do CPC), inclusive a interrupção do prazo prescricional (conclusão majoritária)"'.

Na ocasião, interpretei o artigo 174 do Código Tributário, assim redigido:

1 O fato gerador do ICM, Caderno de Pesquisas Tributárias n. 3, 2a tiragem, Ed. ResenhaTributária/CEU, p. 431/6. 
"A ação para cobrança do crédito tributário prescreve em 5 anos, contados da data da sua constituição definitiva.

$\S$ único. A prescrição se interrompe:

I. pela citação pessoal feita ao devedor;

II. pelo protesto judicial;

III. por qualquer ato judicial que constitua em mora o devedor;

IV. por qualquer ato inequivoco ainda que extrajudicial, que importe em reconhecimento do débito pelo devedor",

dizendo que:

"Entendemos, pois, que o legislador poderia aumentar ou diminuir o prazo decadencial, como o fez e o faz de acordo com as características próprias de cada tipo de lançamento, mesmo quando de forma paternal com os erros fiscais, no caso do item II do artigo 173. A regra básica é o primeiro dia do exercício seguinte, podendo ser menor (expressamente artigo $150, \S 4^{\circ}$ ou único do artigo 173 do CTN, ou quando a lei ordinária o determinar) ou maior (única hipótese, a do item II do artigo 173).

Acrescentamos que, na hipótese do artigo $150, \S 4^{\circ}$, a nosso ver, permite a lei complementar que a lei ordinária ultrapasse o prazo de 5 anos da ocorrência do fato gerador para o primeiro dia do exercício seguinte ao que o lançamento poderia ter sido efetuado.

É aliás, este artigo repleto de outras aparentes incongruências, como por exemplo a do seu $\S 1^{\circ}$ :

'Art. 150 ........

$\S 1^{\circ} \mathrm{O}$ pagamento antecipado pelo obrigado nos termos deste artigo extingue o crédito, sob condição resolutória da ulterior homologação do lançamento",

eis que não pode falar na extinção de um crédito ainda não constituído, mas apenas de uma extinção imediata após a constituição, com o que o lançamento se justifica. Evidentemente o que o dispositivo quer dizer, ao falar em crédito tributário extinto sob condição resolutória, que o pagamento se transforma em crédito tributário apenas quando do lançamento $e$ neste momento se extingue. É aliás, o sentido do item VII do artigo 156 do CTN, ao rezar:

“Art. 156 - Extinguem o crédito tributário: 
$V$ - o pagamento antecipado e a homologação do lançamento, nos termos do disposto no art. 150 e seus $\S \S 1^{\circ}$ e $4^{o " ;}$;

valendo como fórmula de encerramento, em ocorrendo, concomitantemente, o pagamento e a homologação.

Poder-se-ia levantar a objeção de que o Código Tributário Nacional cuida de uma decadência extintiva de crédito tributário (item V, artigo 156), o que poderia parecer um absurdo. Entendemos, todavia, de que a decadência a que se refere o inciso $V$, com efeitos extintivos do crédito tributário é aquela do item II do artigo 173, eis que o mesmo foi constituído e anulado o lançamento, por vicio formal.

Reconhecemos, todavia, a deficiente redação legislativa, que se completa com a interpretação atrás exposta.

Compostas as aparentes divergências do texto complementar e compreendidos os seus dispositivos como um todo harmônico, onde te mos uma constituição definitiva do crédito tributário com o lançamento, nos termos definidos no artigo 142 do CTN assim como um prazo decadencial para constituí-lo, mais ou menos elástico, conforme a modalidade do lançamento, mas nunca inferior a 5 anos a partir da ocorrência do fato gerador. a não ser que a lei ordinária disponha em contrário, passemos ao exame daquele que nos parece o problema crucial da questão, qual seja o de saber se em relação ao crédito tributário, definitivamente constituído, somente pode haver interrupção da prescrição ou esta também pode ser suspensa.

Neste particular, apesar de reconhecer a não aceitação pela doutrina da posição que assumimos, confessamos que não nos convencemos dos argumentos que nos foram opostos se não vejamos:

A nossa posição a de que, uma vez constituído o crédito tributário pelo lançamento, começa a correr um prazo fatal de 5 anos para prescrever $o$ direito à ação, a não ser que seja interrompido por uma das quatro hipóteses mencionadas no §único do artigo 174.

"Parágrafo único - A prescrição se interrompe;

I - pela citação pessoal feita ao devedor;

II - pelo protesto judicial;

III - por qualquer ato judicial que constitua em mora o devedor;

IV - por qualquer ato inequivoco, ainda que extra-judicial, que importe em reconhecimento do débito pelo devedor: 
Entendemos, por outro lado, que a suspensão da exigibilidade do crédito tributário, com efeitos apenas administrativos, não tem o condão de paralisar a fluência do prazo prescricional, para tanto devendo a Fazenda, se suspensa a exigibilidade do crédito tributário, utilizar-se do protesto judicial, como forma interruptiva da prescrição.

Entendemos que somente neste contexto tem sentido a medida proposta pelo legislador no item II, eis que, se não suspensa a exigibilidade do crédito tributário, a Fazenda não tem que protestar o seu direito, mas executá-lo, sendo inócua, nesta hipótese, a enunciação legislativa do protesto.

Entendemos que se, na legislação processual e civil, a falta de exigibilidade torna o direito liquido e certo inexecutável, o legislador tributário, nesta hipótese, inovou, eis que exigiu apenas a constituição do crédito tributário como passo primeiro da fluência prescricional e remediou a falta de exigibilidade pela outorga do direito ao protesto.

E, finalmente, que, assim agindo, limpou, definitivamente, o campo da arbitrariedade, que incluiria entre a decadência e a prescrição um terce-iro estágio (suspensão da exigibilidade do crédito tributário), este sem prazo definido, multiplicando ao infinito o prazo entre a ocorrência do fato gerador e a propositura da ação de execução fiscal" 2 .

Ruy Barbosa Nogueira encampou a tese, em seu livro "Curso de Direito Tributário", e até mesmo, numa primeira aproximação, o ministro Moreira Alves, embora tenha alterado sua posição, posteriormente, para admitir um prazo infinito entre o fim do prazo decadencial, pelo início do lançamento (art. 142 e 145 do CTN), e o encerramento do processo administrativo, a que denominou de "constituição definitiva", para, nos lançamentos de ofício, começar a contagem do prazo prescricional.

A medida em que os lançamentos por declaração passaram a ser substituídos pelos lançamentos por homologação - hoje raro é o tributo em que o lançamento é por declaração - e que se principiou a discutir a dupla mão da punição inercial, seja na exigibilidade do crédito tributário, seja nos pedidos de repetição do indébito, ganhou relevância a questão da contagem do prazo, nestes lançamentos, para saber-se se a prescrição ocorreria a partir do nascimento da obrigação tributária, com a ocorrência do fato gerador e pagamento antecipado pelo contribuinte, independente de manifestação da Administração, ou se, a partir dos cinco anos decorridos para a homologação.

Embora, pessoalmente, não consiga vislumbrar como STF e STJ conseguiram ver, no $\S 4^{\circ}$ do art. 150 do CTN, que a prescrição passaria a ocorrer a partir dos 5 anos da homologação, firmou-se, no STJ, a jurisprudência de que tanto para pleitear

2 Caderno de Pesquisas Tributárias, vol. 1, Decadência e Prescrição, Ed. Resenha Tributária/CEU, $3^{2}$. tiragem, p. 196/8. 
a restituição, quanto para cobrar, conta-se 5 anos até a homologação do pagamento e 5 anos após este prazo ${ }^{3}$.

Confesso que não consigo chegar à interpretação do STJ, em face das expressões " a contar da ocorrência do fato gerador" e "fica definitivamente extinto o crédito", o que vale dizer, sendo coerente com o disposto no artigo 156, incisos V e VII, do CTN, assim redigido:

\section{"Extinguem o crédito tributário:}

$V$ - a prescrição e a decadência;

VII - o pagamento antecipado e a homologação do lançamento nos termos do disposto no art. 150 e seus $\S 1^{\circ}$ e $4^{\circ}$;".

A prescrição e a decadência são formas de extinção do crédito tributário. Se a prescrição extingue o crédito, como se pode falar que a extinção, determinada pela homologação, não é a mesma extinção da prescrição? Apenas se trabalharmos, com uma contradição em termos, é que se pode afirmar que a extinção decorrente da homologação é uma "extinção não extintiva", pois poderá ainda ser exigido o crédito extinto e a "extinção da prescrição" é uma extinção extintiva, porque já não se pode mais exigir o tributo. Com todo o respeito aos eminentes ministros do STJ e do STF, não aceito o hermafroditismo do vocábulo "extinção", que ora é, ora não é o que declara ser, ou seja, "extinção" 4 .

Dir-se-á que a decadência não extingue o crédito tributário porque este não chegou a nascer. Pensei, desta forma, no passado, mas não penso mais atualmente,

3 Ricardo Lobo Torres, criticando a redação, afirma, todavia, que: "O CTN cria, no art. 150, a figura do lançamento por homologação, que abrange a antiga concepção de autolançamento, tanto criticada pela doutrina em virtude de o lançamento, a rigor, ser ato praticado pela Administração. O caput do art. 150 diz que o lançamento por homologação, que ocorre quanto aos tributos cuja legislação atribua ao sujeito passivo o dever de antecipar o pagamento sem prévio exame da autoridade administrativa, opera pelo ato em que a referida autoridade, tomando conhecimento da atividade assim exercida pelo contribuinte, a homologa. No $\S 4^{\circ}$ do art. 150 está previsto que, se a lei não fixar prazo à homologação, será ele de 5 anos, a contar da ocorrência do fato gerador; expirado esse prazo sem que a Fazenda Pública se tenha pronunciado, considera-se homologado o lançamento e definitivamente extinto o crédito, salvo se comprovada a ocorrência de dolo, fraude ou simulação.

O art. 156, VII, fazendo expressa remissão ao dispositivo que cuida do lançamento por homologação prevê que extinguem o crédito tributário "o pagamento antecipado e a homologação do lançamento" (Comentários ao Código Tributário Nacional, Ed. Saraiva, ed. 2002, p. 336/7).

$4 O \$ 4^{\circ}$ do art. 150 está assim redigido: "Se a lei não fixar prazo à homologação, será ele de 5 anos, a contar da ocorrência do fato gerador, expirado esse prazo sem que a Fazenda Pública se tenha pronunciado, considera-se homologado o lançamento e definitivamente extinto o crédito. salvo se comprovada a ocorrência de dolo, fraude ou simulação" (destaques meus). 
visto que a decadência, ao extinguir a obrigação tributária que tem a mesma natureza do crédito tributário, afasta um "ato em potência", na concepção de Tomás de Aquino, ou seja, o crédito de possível constituição, o qual termina não se transformando em ato, por extinção prévia da obrigação.

Por esta razão, volto a reverenciar os autores do CTN — todos juristas de escol, como já não se produzem mais, nos bastidores dos regulamenteiros atuais - entendendo que não houve um cochilo legislativo, ao se estabelecer que a decadência e a prescrição extinguem o crédito tributário, e, nos termos utilizados para o $\S 4^{\circ}$ do art. 150, com o decurso de prazo de 5 anos, com uma única exceção para os casos de dolo ou de fraude.

Apesar de estar convencido de que Rubens Gomes de Souza, Gilberto de Ulhôa Canto, Carlos da Rocha Guimarães, Tito Rezende, Aliomar Baleeiro - dos quais fui contemporâneo mais jovem - não embarcariam na interpretação dos dignos Ministros do Superior Tribunal de Justiça, curvo-me - na condição de modesto operador provinciano do Direito - à jurisprudência firmada, visto que posso dar apenas opiniões, enquanto SS.Exas. podem fazer o direito.

$E$, neste particular, hoje a jurisprudência dominante é aquela tão bem situada, em síntese perfeita pela Ministra Eliana Calmon:

"Processo RESP 614110

Relator(a) Ministra ELIANA CALMON

Data da Publicação: DJ 19.05.2004

Decisão

RECURSO ESPECIAL No 614.110 - RS (2003/0217892-9)

RELATORA : MINISTRA ELIANA CALMON

RECORRENTE: INSTITUTO NACIONAL DO SEGURO SOCIAL - INSS

PROCURADOR: MÁRCIA PINHEIRO AMANTEA E OUTROS

RECORRIDO: IRMA GAZOLA - MICROEMPRESA E OUTROS

ADVOGADO: RICARDO JOSUÉ PUNTEL

\section{DECISÃO}

TRIBUTÁRIO - PRESCRIÇÃO - TRIBUTO LANÇADO POR HOMOLOGAÇÃO - TERMO INICIAL - TESE DOS "CINCO MAIS CINCO" PACIFICAÇÃO DE ENTENDIMENTO - EREsp 435.835/SC.

Trata-se de recurso especial interposto de acórdão que decidiu em torno da prescrição de tributo lançado por homologação.

Alega-se, em síntese, que deve prevalecer a tese da contagem do prazo prescricional a partir da declaração de inconstitucionalidade pela Suprema Corte.

\section{DECIDO:}

Sobre a prescrição dos tributos lançados por homologação, a jurisprudência do STJ oscilou durante algum tempo, assumindo as seguintes posições: 
$I^{a}$ etapa - o Fisco tem até cinco anos para homologar o seu crédito e mais cinco para exigi-lo, na ausência de homologação. Por um raciocínio simplista, inaugurou-se a tese dos "cinco mais cinco", contando-se dez anos a partir do fato gerador (os cinco primeiros anos, prazo decadencial, e os cinco restantes, prazo prescricional).

Nesse sentido, dentre outros presedentes, citam-se os seguintes julgados: REsp 75.006/PR, REsp 69.233/RN, EREsp 43.502/RS, REsp 266.889/SP, AgRg/AG 317.687/SP, AgRg/REsp 256.344/DF e REsp 250.753/PE;

$2^{a}$ etapa - inicia-se o prazo prescricional a partir da declaração de inconstitucionalidade pelo Supremo Tribunal Federal. Esta posição abrigava variantes, no que se refere ao termo a quo: data do julgamento, do trânsito em julgado ou do ajuizamento da ação.

- Advirta-se que não importa, para os adeptos desta tese, se a declaração de inconstitucionalidade ocorreu em controle difuso ou concentrado. Dai os precedentes, dentre outros, o REsp 220.469/AL, REsp 209.903/AL, EREsp 43.205/RS e AgRg/REsp 252.846/DF;

$3^{a}$ etapa - no REsp 329.444/DF, a Primeira Seção deliberou que o termo a quo em comento inicia-se da data do trânsito em julgado no qual o Supremo Tribunal Federal declarou a inconstitucionalidade da lei pela primeira vez;

$4^{a}$ etapa - a Primeira Seção, no EREsp 423.994/MG, realinhou o entendimento para concluir que, quando se tratar de controle difuso, inicia-se a contagem da data da Resolução do Senado e, quando se tratar de controle concentrado, a partir do trânsito em julgado da ADIn.

Finalmente, no julgamento do EREsp 435.835/SC, cujo acórdão será lavrado pelo Ministro José Delgado, consagrou-se definitivamente a tese dos "cinco mais cinco", diante das perplexidades causadas pela a adoção de outras teses. Portanto, considerando-se que o tributo em tela está sujeito ao chamado "autolançamento", o Fisco pode homologá-lo expressa ou tacitamente. Não havendo prazo fixado em lei para a homologação, ela será de até 5 (cinco) anos, a contar da ocorrência do fato gerador (art. 150, § $4^{\circ}$, do $(T N)$. A extinção do crédito tributário ocorrerá com a homologação e não com o pagamento antecipado, quando então deverá fluir o prazo prescricional de 5 (cinco) anos previsto no art. 168, inciso I, do CTN. Neste sentido:

\section{TRIBUTÁRIO - LANÇAMENTO POR HOMOLOGAÇÃO - DECADÊN- CIA - PRAZO.}

Já é pacífico no STJ o entendimento de que o prazo decadencial de 05 anos deve ser contado a partir da homologação do lançamento do crédito tributário, e se a lei não fixar prazo para homologação, será ele de 05 anos a contar da ocorrência do fato gerador. 
Embargos recebidos (EREsp 170.834/SP, reI. Min. Garcia Vieira, Primeira Seção, unânime, DJ 15/03/99, pág. 79).

TRIBUTÁRIO E PROCESSUAL. CONTRIBUIÇÃO PREVIDENCIÁRIA. ADMINISTRADORES E AUTÔNOMOS. PRESCRIÇÃO DAS PARCELAS. INOCORRENCIA. PRECEDENTES.

Nos tributos lançados por homologação, a prescrição do direito de pleitear sua restituição ou compensação só ocorre após expirado o prazo de cinco anos, contados do fato gerador, acrescidos de mais cinco anos, a partir da homologação tácita. Este o entendimento consagrado nas duas Turmas da Primeira Seção do STJ.

Declarada a inconstitucionalidade da exação, sua exclusão do ordenamento jurídico ocorreu desde quando instituída. Assim, não há falar em prescrição das parcelas recolhidas mas, sim, da própria ação que, na hipótese, não ocorreu devido à data do seu ajuizamento.

Recurso especial conhecido, porém, improvido.

(REsp 199.703/CE, reI. Min. Francisco Peçanha Martins, Segunda Turma, unânime, DJ 18/10/99, pág. 224)

TRIBUTÁRIO. COMPENSAÇÃO. CORREÇÃO MONETÁRIA. PRESCRIÇÃO. TEMAS PACIFICADOS NO STJ.

- Em tema de compensação, a correção monetária, segundo reiterado entendimento do STJ, deve ser calculada tendo como indexador o IPC, para o periodo de março/90 a janeiro/91; o INPC, relativamente ao de fevereiro/91 a dezembro/91; e, com base na UFIR, a partir de janeiro de 1992.

- $O$ índice de janeiro de 1989 é de 42.72\% (REsp. 43.055-0-SP).

- "No lançamento por homologação, a prescrição do direito de pleitear sua restituição se dá após o prazo de cinco anos, contados do fato gerador, acrescidos de mais cinco anos, a partir da homologação tácita".

(REsp. 206.503/SP, reI. Min. Humberto Gomes de Barros, Primeira Turma, unânime, DJ 02(08/99, p. 159).

TRIBUTÁRIO - REPETIÇÃO DE INDÉBITO - ADICIONAL DO IMPOSTO DE RENDA - DECADENNCIA - TERMO INICIAL - JUROS MORATÓRIOS - PERCENTUAL E TERMO "A QUO" - CTN, ARTS. I6I E 167 - SÚMULA 188/STJ - PRECEDENTES.

- Sendo o Adicional do Imposto de Renda espécie de tributo sujeito a lançamento por homologação, a decadência do direito de pleitear a resti- 
tuição só ocorrerá após decorridos cinco anos da ocorrência do fato gerador, somados de mais 5 anos, contados da homologação tácita, já que não houve homologação expressa.

- Tratando-se de repetição do indébito tributário, os juros moratórios são devidos no percentual de $1 \%$ ao mês, a partir do trânsito em julgado da sentença.

- Recurso provido parcialmente.

(REsp 153.513/RJ, reI. Min. Francisco Peçanha Martins, Segunda

Turma, unânime, DJ 22/05/2000, pág. 94).

PROCESSUAL CIVIL E TRIBUTÁRIO. RECURSO ESPECIAL. IMPOSTO DE RENDA. FÉRIAS, LICENÇAS-PREMIO E ABONOS-ASSIDUIDADE. VERBAS INDENIZATÓRIAS. NÃO INCIDÊNCIA. PRESCRIÇÃO. ACÓRDÃO RECORRIDO EM DISSONÂNCIA COM A ORIENTAÇÃO DESTA TURMA. HONORÁRIOS. FIXAÇÃO AQUÉM DO MÍNIMO LEGAL. POSSIBILIDADE. PRECEDENTES.

- Nos termos da jurisprudência consolidada no âmbito desta Primeira Turma, o prazo para que seja pleiteada a restituição do imposto de renda incidente sobre valores referentes a verbas de caráter indenizatório começa a fluir decorridos 5 (cinco) anos, contados a partir da ocorrência do fato gerador, acrescidos de mais um qüinqüênio computados desde o termo final do prazo atribuído ao Fisco para verificar o quantum devido a título de tributo.

- A fixação dos honorários advocatícios em percentual inferior ao mínimo estabelecido pelo $\S 3^{\circ}$, art. 20, do CPC, quando sucumbente é a Fazenda Pública, porquanto não se trata de um ente concreto, mas sim da própria comunidade, representada pelo governante, merecendo, portanto, tratamento especial.

- Recurso parcialmente provido.

(REsp 329.833/DF, reI. Min. Luiz Fux, Primeira Turma, unânime, DJ 22/04/2002, pág. 164).

Com essas considerações, nos termos do art. 557 do CPC, NEGO SEGUIMENTO AO RECURSO ESPECIAL.

Brasília-DF, 05 de maio de 2004.

Ministra Eliana Calmon

Relatora"s. 
Como nem a minha interpretação do art. 174 do CTN prevaleceu no STF, nem a do $\S 4^{\circ}$ do art. 150 no STJ, começo a chegar à conclusão de que, tal como os meus velhos mestres e amigos (já falecidos) formatadores do direito tributário no Brasil, viram suas teses superadas pelas novas concepções do Judiciário e da doutrina que meu tempo, em que o raciocínio lógico prevalecia, já foi ultrapassado pela originalidade dos novos tempos, em que a lógica e a coerência têm caminhos diversos do que aqueles que nós, os velhos, costumávamos vislumbrar. É que sempre entendemos que a prescrição e a decadência são formas de punir a inércia e gerar segurança jurídica, e quanto mais distendido for o prazo de ocorrência mais inseguro será o direito.

Modestíssimo advogado de Província, faço estas considerações românticas (e, talvez, nostálgicas), reverenciando o tempo em que o direito era mais seguro e tanto o presente quanto o futuro seguiam uma lógica mais previsível. Hoje, entretanto, no país dos "esqueletos econômicos", a todo momento redescobertos pelo Judiciário, e da incerteza jurídica distendida no tempo, creio que outro amigo falecido (Roberto Campos) de quem fui, quando jovem, contemporâneo e co-autor de obras, tinha razão. No Brasil de hoje, tanto o futuro como o passado são imprevisíveis - com a decisiva colaboração dos eminentes ministros dos Tribunais Superiores ${ }^{6}$.

6 Destaco ementa com duplo critério para determinação do prazo decadencial e prescricional. à luz do direito de constituir o crédito tributário e repetir ou compensar o crédito indevido:

"RECURSO ESPECIAL No250.753 - PERNAMBUCO (2000/0022497-9)

RELATOR : MIN. GARCIA VIEIRA

RECTE : FAZENDA NACIONAL

PROC. : WALTER GIUSEPPE MANZI E OUTROS

RECDO : HACATA COMERCIO E INDUSTRIA L TDA.

DVOGADO : JOSE AIRTON SOARES COELHO

EMENTA: TRIBUTÁRIO - FINSOCIAL - COMPENSAÇÃO - PRESCRIÇÃO DECADENCIA.

É pacifico no Superior Tribunal de Justiça o entendimento de que, não havendo lançamento por homologação ou qualquer outra forma, o prazo decadencial só começa a correr após decorridos cinco anos da ocorrência do fato gerador, somados mais 05 (cinco) anos.

O prazo prescricional de cinco anos para a compensaçäo ou cobrança do crédito correspondente aos recolhimentos indevidos só começa a fluir da data da decisäo do Supremo Tribunal Federal que declarou a inconstitucionalidade da contribuição para o FINSOCIAL (RE $n^{\circ}$ 159.764-1).

Recurso improvido" (STJ, D.J. 14/08/2000). 